\title{
An Empirical Study on the Regional Distribution and Influencing Factors of Community Development Foundations -- Take Shanghai as an Example
}

\author{
Siyang Zhang ${ }^{1, *}$ \\ ${ }^{1}$ School of Public management, Southwest Minzu University, Sichuan 610200, China \\ *Corresponding author. Email:854948051@qq.com
}

\begin{abstract}
Community development foundations have significant advantages in integrating community public resources, cultivating community public welfare projects, meeting the needs of community residents for survival and safety, participating in community governance at the grassroots level, enhancing community cultural integration, expanding social public welfare capital and promoting community development.Based on the investigation of Shanghai Community Development Foundation, it is found that its regional distribution is related to the number of population, the degree of economic development, the density of population, the degree of government support and other factors, which is of practical significance for the promotion of community development foundations in grassroots communities in China.
\end{abstract}

Keywords: community development foundation, Regional distribution, Grassroots governance

\section{INTRODUCTION}

By the end of 2019, there are 181 community development foundations in China, among which Shanghai, Guangzhou and Jiangsu are affected by regional advantages. Among them, Shanghai, with an absolute advantage of 96 community development foundations, stands at the forefront of China's exploration of the localization model and mechanism innovation of community development funds. Shanghai is located in the eastern part of China, and Jiangsu and Zhejiang provinces join. Under the Huangpu District, Hongkou District and other 16 municipal districts. In general, the number of community development foundations in Shanghai presents an unbalanced state, among which Pudong New Area has the largest number. By the end of 2019, there were 15 community development foundations, accounting for $15.62 \%$ in Shanghai. Qingpu District has the lowest number of community development foundations, accounting for 2.08 percent of Shanghai's total by the end of 2019, a gap of 7.5 times. At the same time, the regional distribution of community development foundations in Shanghai is unbalanced, and most of them are concentrated in a few municipal districts such as
Huangpu District, Pudong New Area and Jing 'an District. The top five municipal districts have community development foundations accounting for $87.5 \%$ of the total.However, while the number of community development foundations in Shanghai has doubled, they are also characterized by "small scale, less funds and strong dependence", which leads to the weak long-term sustainable development ability of community development foundations and the imbalance of regional development. Therefore, it is of practical significance to conduct research on the quantitative and regional distribution of community development foundations in Shanghai to explore the influencing factors of the development of community development foundations, so as to promote the benign localized development of community development foundations.

\subsection{Literature review}

The first is the research on the definition and characteristics of community development foundation. Community Development Foundations (CDFs) were born in the United States and developed mainly in the United States. Other countries, including China, have gradually explored and developed based on the 
experience of CDFs in the United States and combined with their own national realities and different regional needs. ${ }^{[1]}$ In the United States and European countries, the definition of community development foundation is: a tax-exempt, self-governing, non-profit, public support charity organization. Usually, they are charitable organizations initiated and founded by single or multiple members of the community with the participation and assistance of other social organizations, with the purpose of safeguarding the rights of community members and creating social values (Kilmurray, $2015)^{[2]}$.Current home in the definition of community development foundation, usually refers to a certain area (usually in the street or community as a unit) of residents to establish the foundation with the regional limit properties and community public welfare organizations, through assistance in the area of social organizations (banking model community development fund) or run by social public welfare project (aggregation model community development fund), in order to solve or alleviate the regional social public problems and safety issues, so as to improve the community members of the community quality of life. Its initial funds are mostly raised through businesses, families, individuals and other institutions within the community.

The second is the research on the function orientation and function of the community development foundation. Western countries consider community development foundations to be organizations that meet the security and development needs of community members through a wide range of social funding and public welfare projects (Brown, 2006) [].1 In China, community development foundations are regarded as a reservoir of community public welfare resources, a booster of community public welfare, a platform for community members to effectively participate in community grass-roots governance, and an incubator for social organization cultivation (Cui Kaiyun, 2015) ${ }^{[3]}$.

The last part is about the research of the development model of community development foundation. The American society usually divides the operation mode of community development foundation into the incubator community development foundation and the operation community development foundation. As the name implies, incubation-type community development foundations are similar to the definition of capital pool of community development foundations in China. They raise community resources through community development foundations and provide financial support and professional guidance to social organizations within the community. Operational community development foundations refer to foundations that operate community public welfare projects on their own. According to the resource-dependent theory, the domestic division of the development mode of community development foundations is mainly divided into three types: government-led, enterture-led and resident autonomous (Xu Jialiang, 2016 ${ }^{[4]}$.The community development foundations in Shanghai are mainly government-led and residents self-governing. ${ }^{[5]}$

\subsection{Analysis framework}

As a new participant in the community governance system, the establishment and development of community development foundations are bound to be influenced by other participants and external factors. These include government entities, service audiences, and external factors. ${ }^{[6]}$ Under the guidance of the current new model of community governance of "Party leadership and government management", the relevant policy and financial support of the government for community development foundations is of great importance for the community development foundations at the initial stage. ${ }^{[7]}$ The social audience is not only the service object of the community development foundation, but also the carrier of its existence. The participation of community members is of practical significance for the diversification of the fund donation channels of the community development foundation and the expansion of volunteer participation. At the same time, external environmental and economic factors also have a potential impact on community development funds. ${ }^{[8]}$

\subsection{Research ideas}

The research scope of this study is defined in Shanghai, mainly because of the early start time and relatively mature development scale of Shanghai Community Development Foundation. The research object is defined as the number distribution of Shanghai community development foundations in each municipal district. Factors in lai (2017)on advanced on the basis of the analysis of main factors affecting the development of social organization, choose the area of population, economic development level, government support, such as three variables, at the same time, increasing the government's urban and rural community in the general public finance budget category annual implementation and regional population density of two variables, in order to analyze the Shanghai municipal districts of the community development fund development degree.

At the same time, four hypotheses are proposed for this study:

Theoretical hypothesis H1: the greater the government policy and financial support in the administrative area, the more the number of development of community development foundations in the region, the government policy support and financial 
support (urban and rural community expenditure) in the administrative area is positively correlated with the number of community development foundations;

Theoretical hypothesis H2: the greater the number of population in the administrative area, the more the number of development of community development funds in the region, and the number of population in the administrative area is positively correlated with the number of community development funds;

Theoretical hypothesis H3: the greater the population density in the administrative area, the more the number of development of community development foundations, the population density in the administrative area is positively correlated with the number of community development foundations;

Theoretical hypothesis H4: the higher the GDP under the administration, the more the number of development of community development funds, and the annual GDP of the administrative area is positively correlated with the number of community development funds.

Model establishment:

Assuming that the relationship between the number of community development foundations in Shanghai and (such factors as the number of population, degree of economic development, population density and government support) is linear, the multiple linear regression model is as follows: $y=b 0+b 1 X 1+b 2 \times 2+b 3 \times 3+b 4 X 4+e$

Where Y represents the number of community development foundations in each district of Shanghai, $\mathrm{X} 1$ represents the population level in the district, $\mathrm{X} 2$ represents the economic development level in the district, X3 represents the population density level in the district, and $\mathrm{X} 4$ represents the financial support from the government.b0Is a constant term, $\mathrm{E}$ is a random error.

Data source: Through sorting and statistical analysis of the basic data published by China Social Organization Publicity Service Platform, Ministry of Civil Affairs Data Center, China Foundation Center Network, Shanghai Civil Affairs Bureau and Shanghai Municipal Government Network, the required community foundation data, population data, GDP data, population density data and so on were obtained. The economic degree is measured by GDP. The government supports the adoption of the relevant community development fund policies issued by the government and the implementation of urban and rural community financial expenditure in each district of Shanghai in 2019 as the measurement indicators.

\section{BACKGROUND}

After using the data analysis software tool SPSS to make an empirical analysis of the data, the summary table of the main variable data, variance analysis results and regression equation coefficients are shown in Figure (1), (2) and (3) below. As shown in Fig. (1) : correlation coefficient $\mathrm{R}=0.945$, determination coefficient $\mathrm{R} 2=0.893$, adjusted $\mathrm{R} 2=0.855$, standard error of regression estimation $\mathrm{S}=1.157, \mathrm{D}-\mathrm{W}=1.462$.It is proved that the regression effect of the sample is better.Figure (2) shows the table of variance analysis. From the partial analysis results, it can be concluded that the statistic $\mathrm{F}=23.038$ and the significance level $\mathrm{P}=0.000<0.05$ prove that the linear relationship between the dependent variable and the independent variable is obvious. Figure (3) shows the regression coefficient analysis results, and the multiple linear regression equation can be obtained as follows: $\mathrm{Y}=3.306+0.075 \times 1+3.075 \times 2+2.699 \times 3+$ $1.015 \times 4+\mathrm{E}$.

Table 1 summary table of data models

\begin{tabular}{|c|c|c|c|c|c|c|c|c|c|c|}
\hline \multirow[b]{6}{*}{ model } & \multirow[b]{6}{*}{$\mathrm{R}$} & \multirow[b]{6}{*}{ R party } & \multirow[b]{3}{*}{ R squared } & \multirow[b]{4}{*}{ Error in } & \multicolumn{5}{|c|}{ Change the statistical } & \multirow{6}{*}{$\begin{array}{l}\text { Durbin } \\
\text { Watson }\end{array}$} \\
\hline & & & & & \multicolumn{5}{|c|}{2} & \\
\hline & & & & & \multicolumn{5}{|c|}{ Degrees degrees } & \\
\hline & & & \multirow{2}{*}{$\begin{array}{c}\text { after } \\
\text { adjustmen }\end{array}$} & & & & of & of & Change in & \\
\hline & & & & standard & Change in & $\mathrm{F}$ & \multicolumn{3}{|c|}{ freedom freedom significance } & \\
\hline & & & $\mathrm{t}$ & estimates & \multicolumn{2}{|c|}{$\mathrm{R}$ squared variation } & 1 & of & $\mathrm{F}$ & \\
\hline 1 & 945.a & 893. & 855. & 1.157 & 893. & 23.038 & 4 & 11 & 000. & 1.462 \\
\hline \multicolumn{11}{|c|}{ A. Predictive variables :(constant), GDP, population density, population size, urban finance } \\
\hline \multicolumn{11}{|c|}{ B. Dependent variable: quantity of regional distribution } \\
\hline
\end{tabular}


Table 2 Results of ANOVA

\begin{tabular}{|c|c|c|c|c|c|c|}
\hline \multicolumn{2}{|c|}{ model } & $\begin{array}{l}\text { Sum of } \\
\text { squares }\end{array}$ & $\begin{array}{c}\text { Degrees of } \\
\text { freedom }\end{array}$ & $\begin{array}{c}\text { The mean } \\
\text { square }\end{array}$ & $F$ & significant \\
\hline \multirow[t]{3}{*}{1} & $\begin{array}{l}\text { Return to } \\
\text { the }\end{array}$ & 123.284 & 4 & 30.821 & 23.038 & 000.b \\
\hline & residual & 14.716 & 11 & 1.338 & & \\
\hline & A total of & 138.000 & 15 & & & \\
\hline \multicolumn{7}{|c|}{ A. Dependent variable: quantity of regional distribution } \\
\hline \multicolumn{7}{|c|}{$\begin{array}{l}\text { B. Predictive variables :(constant), GDP, population density, population size, urban } \\
\text { finance }\end{array}$} \\
\hline
\end{tabular}

Table 3 regression equation coefficients

\begin{tabular}{|c|c|c|c|c|c|c|c|c|}
\hline \multirow{3}{*}{\multicolumn{2}{|c|}{ model }} & \multicolumn{2}{|c|}{$\begin{array}{c}\text { Unnormalized } \\
\text { coefficient }\end{array}$} & \multirow[t]{2}{*}{$\begin{array}{l}\text { Normalized } \\
\text { coefficient }\end{array}$} & \multirow[b]{3}{*}{$\mathrm{t}$} & \multirow[b]{3}{*}{ significant } & \multicolumn{2}{|c|}{ Collinear statistics } \\
\hline & & \multirow[b]{2}{*}{ B } & Standard & & & & \multirow{3}{*}{ tolerance } & \multirow{3}{*}{ VIF } \\
\hline & & & error of & Beta & & & & \\
\hline \multirow[t]{5}{*}{1} & (constant) & 3.306 & 846. & & 3.910 & 002. & & \\
\hline & $\begin{array}{c}\text { population } \\
\text { The }\end{array}$ & 075. & 047. & 036. & 756. & 465. & 145. & 6.918 \\
\hline & $\begin{array}{c}\text { population } \\
\text { density }\end{array}$ & 2.699 & 1.573 & 950. & 2.926 & 014. & 678. & 1.475 \\
\hline & $\begin{array}{c}\text { City } \\
\text { financial }\end{array}$ & 1.015 & 912. & 778. & 1.283 & 226. & 111. & 8.970 \\
\hline & GDP & 3.072 & 2.796 & 909. & 3.678 & 004. & 066. & 15.135 \\
\hline De & dent varia & quan & region & ibution & & & & \\
\hline
\end{tabular}

There is a significant positive correlation between government financial support and the development quantity of Shanghai Community Development Foundation, and theoretical hypothesis H1 is established.

From the estimated results of the regression on the $\mathrm{Y}$ axis plane distance was 3.306, city financial support degree of regression coefficient estimate is 2.699, under the condition of controlling other variables, promotes each city financial support level 1 units, or $1 \%$, jurisdiction community development fund quantity increases 2.699 units, namely $2.699 \%$. It can be concluded that the number distribution of community development foundations is positively correlated with the level of urban financial support.Urban and rural community expenditure refers to the expenditure directly used by the government for urban and rural community affairs. At present, the municipal governments of Shanghai mainly entrust non-profit social organizations such as community development foundations to provide community public services in the form of government purchase. It is for this reason that the implementation of the annual urban and rural community financial budget of each municipal district in Shanghai directly reflects the financial support that the government can use to support the community development foundation and other non-profit organizations.

There is a significant positive correlation between the area population and the development quantity of Shanghai Community Development Foundation, and the theoretical hypothesis $\mathrm{H} 2$ is established.It can be seen from the estimated results that the intercept of the regression plane on the $\mathrm{Y}$ axis is 3.306, and the regression coefficient of the area population is estimated to be 0.075 , which means that under the control of other 
variables, the number of community development foundations in the area will increase by 0.075 units, that is, 0.075 thousand points, for each increase of the area population by 1 unit, that is, 1 percentage point. It can be concluded that there is a positive correlation between the number of district population and the level of community development foundations.

There is a significant positive correlation between the economic development degree of the district and the development quantity of Shanghai Community Development Foundation, and the theoretical hypothesis $\mathrm{H} 3$ is established.From the estimated results of the regression on the $\mathrm{Y}$ axis plane distance of 3.306, the jurisdiction degree of economic development (GDP) estimate of regression coefficient is 3.072, under the condition of controlling other variables, jurisdiction population every increases 1 units, or $1 \%$, jurisdiction community development fund quantity increases 3.072 units, namely $3.072 \%$. It can be concluded that the level of regional economic development is positively correlated with the number of community development foundations.

There is a significant positive correlation between regional population density and the number of development of Shanghai Community Development Foundation, and theoretical hypothesis $\mathrm{H} 4$ is established.It can be seen from the estimated results that the intercept of the regression plane on the $\mathrm{Y}$ axis is 3.306 , and the regression coefficient of the population in the area is estimated to be 2.699 , which means that under the condition of controlling other variables, the number of community development foundations in the area will increase by 2.699 units, that is, 2.699 thousand points, if the population in the area increases by 1 unit, that is, 1 percentage point. It can be concluded that the population density of the district is positively correlated with the number of community development foundations.

\section{CONCLUSION}

The report to the 19th National Congress of the Communist Party of China clearly calls for shifting the focus of social governance to the grassroots level, transforming government functions, and further streamlining administration and delegating power to lower-level governments. The Party and the government have high expectations for social organizations to participate in community grass-roots governance and give full play to their role in social adjustment. As a new type of grassroots governance body, community development foundations have the characteristics of being rooted in the grassroots and being professional. At present, responding to the new requirements of social grass-roots governance in the new situation and exploring the process of localizing the theory and practice of community development foundations in
China are of practical significance for promoting the innovation of the path to the modernization of national grass-roots governance. It is of great significance for promoting government transformation, innovating urban and rural community governance models, and building the social governance concept of "co-construction, co-governance and shared benefits". Although community development foundation is not new, in foreign countries has formed a mature mode of operation and development, but in China, community development foundation is still a new thing, has not yet formed perfect localization of cultivating and developing model construction, but the practice shows that the community development foundation for the innovation of grassroots governance model has practical significance.Promote the development of community foundation research, theory and practice to explore the community development fund in the process of the localization of the influence factors of regional disequilibrium phenomenon, to promote community development foundation of sustainable development with Chinese characteristics and promote the transformation of the main body status in the community governance has practical significance and theoretical value. The author in 2019 in Shanghai community development foundation, the regional distribution differences as the breakthrough point, based on community development foundation, external factors affecting the relationship model of government, society, audience factors and environmental factors, through the analysis of population, regional population density, annual GDP, urban and rural community spending and government information management and so on five indicators of data. The author's four hypotheses on the influencing factors of the development of community development funds have been initially confirmed: the development of community development funds is basically positively correlated with four factors, including the government policy and financial support, the number of regional population, the density of regional population and the degree of regional economic development.Based on this phenomenon, it also exposes the serious imbalance in the regional development of community development funds in China, which forms a great obstacle to the development of community development funds in western China, where the level of regional economic development is low and the population density is high. Innovating the development model of community development foundation and improving the unbalanced phenomenon of regional development are of practical significance for innovating the main body of grass-roots governance in western China.

\section{REFERENCES}

[1] Liu Jianwen. Community Foundations: New Ideas for Promoting Community Autonomy 
Development -- Generation, Characteristics, Localization Construction Strategy and Its Significance [J]. Journal of Yunnan Administration 。

[2] Klimurray A.Community Philanthropy The context,concepts and challenges:A literature review[R].Global Fund For Community Foundations, 2015.

[3] Guo C, Tan W, Wang C, et al.Nonprofit and Voluntary Quarterly,2006,35(2):267-287.

[4] Cui Kaiyun. The American Experience of Community Foundations and Its Enlightenment to China [J]. Jianghuai Forum,2015(04):42-49.

[5] Wang Wei. Community Foundation: A New Idea for the Development of Community Autonomy.Journal of Ningxia Party School,2006(01):32-35 .

[6] Xu Jialiang, Liu Chunshuai. Research on the Operation Mode of Community Foundations in China from the Perspective of Resource Dependence Theory: Based on Shanghai and Shenzhen Cases [J]. Zhejiang Journal,2016(01):216-224.

[7] Zhang Minmin, Xia Jianzhong. Research on the operation mode and development of community foundation in China -- based on the investigation of Shenzhen community foundation [J]. Zhongzhou Academic Journal,2014(12):65-69.

[8] Liu Jianwen. Community Foundations: New Ideas for Promoting Community Autonomy Development -- Generation, Characteristics, Localization Construction Strategy and Its Significance [J]. Journal of Yunnan Administration Institute,2008(03):119-121. 